\title{
A FUNCTIONAL TRANSIENT RECEPTOR POTENTIAL VANILLOID 4 (TRPV4) CHANNEL IS EPXRESSED IN HUMAN ENDOTHELIAL PROGENITOR CELLS
}

\section{This is a pre print version of the following article:}

Original Citation:

Availability:

This version is available http://hdl.handle.net/2318/150134

since 2021-03-11T09:31:04Z

Published version:

DOI: $10.1002 / j c p .24686$

Terms of use:

Open Access

Anyone can freely access the full text of works made available as "Open Access". Works made available under a Creative Commons license can be used according to the terms and conditions of said license. Use of all other works requires consent of the right holder (author or publisher) if not exempted from copyright protection by the applicable law. 


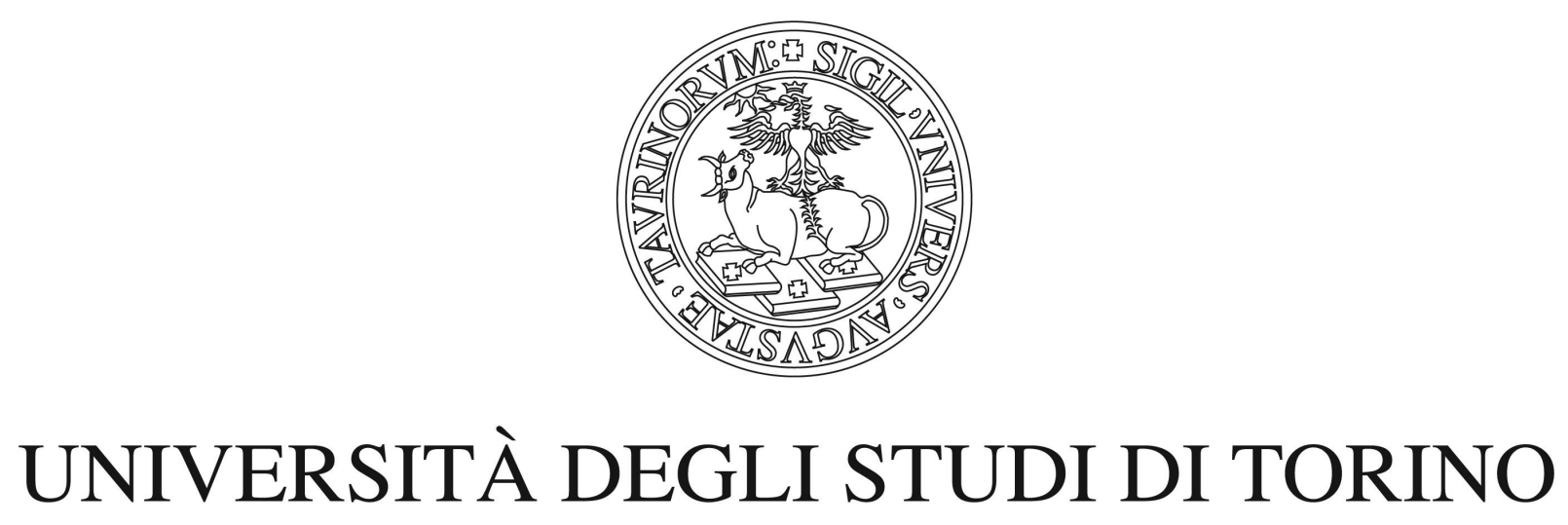

This is an author version of the contribution published on:

Questa è la versione dell'autore dell'opera:

J Cell Physiol. 2015 Jan;230(1):95-104. doi: 10.1002/jcp.24686.

The definitive version is available at:

La versione definitiva è disponibile alla URL:

http://onlinelibrary.wiley.com/doi/10.1002/jcp.24686/abstract;jsessionid=258D80C1

CCFCA8F3E8FC96785A75DBC4.f04t01 


\section{A FUNCTIONAL TRANSIENT RECEPTOR POTENTIAL VANILLOID 4 (TRPV4) CHANNEL IS EXPRESSED IN HUMAN ENDOTHELIAL PROGENITOR CELLS}

\begin{tabular}{|c|c|}
\hline Journal: & Journal of Cellular Physiology \\
\hline Manuscript ID: & JCP-14-0192.R1 \\
\hline Wiley - Manuscript type: & Original Research Article \\
\hline Date Submitted by the Author: & $\mathrm{n} / \mathrm{a}$ \\
\hline Complete List of Authors: & $\begin{array}{l}\text { Dragoni, Silvia; University of Pavia, Biology and Biotechnology "L. } \\
\text { Spallanzani" } \\
\text { Guerra, Germano; University of Molise, Medicine and Health Sciences } \\
\text { Fiorio Plà, Alessandra; University of Turin, Life Sciences and Systems } \\
\text { Biology } \\
\text { Bertoni, Giuseppe; University of Pavia, Biology and Biotechnology "L. } \\
\text { Spallanzani" } \\
\text { Rappa, Alessandra; University of Pavia, Biology and Biotechnology "L. } \\
\text { Spallanzani" } \\
\text { Poletto, Valentina; Foundation IRCCS Policlinico San Matteo, } \\
\text { Bottino, Cinzia; University of Pavia, Molecular Medicine } \\
\text { Aronica, Adele; Foundation IRCCS Policlinico San Matteo, } \\
\text { Lodola, Francesco; University of Pavia, Biology and Biotechnology "L. } \\
\text { Spallanzani" } \\
\text { Cinelli, Maria; University of Naples "Federico II", Public Health } \\
\text { Laforenza, Umberto; University of Pavia, Molecular Medicine } \\
\text { Rosti, Vittorio; Foundation IRCCS Policlinico San Matteo, } \\
\text { Tanzi, Franco; University of Pavia, Biology and Biotechnology "L. } \\
\text { Spallanzani" } \\
\text { munaron, luca; university of Torino, dept. Animal \& Human Biology } \\
\text { Moccia, Francesco; University of Pavia, Physiology }\end{array}$ \\
\hline Key Words: & endothelial progenitor cells, TRPV4, proliferation, GSK1016790A, RN-1734 \\
\hline
\end{tabular}




\section{A FUNCTIONAL TRANSIENT RECEPTOR POTENTIAL VANILLOID 4 (TRPV4) CHANNEL IS EPXRESSED IN HUMAN ENDOTHELIAL PROGENITOR CELLS}

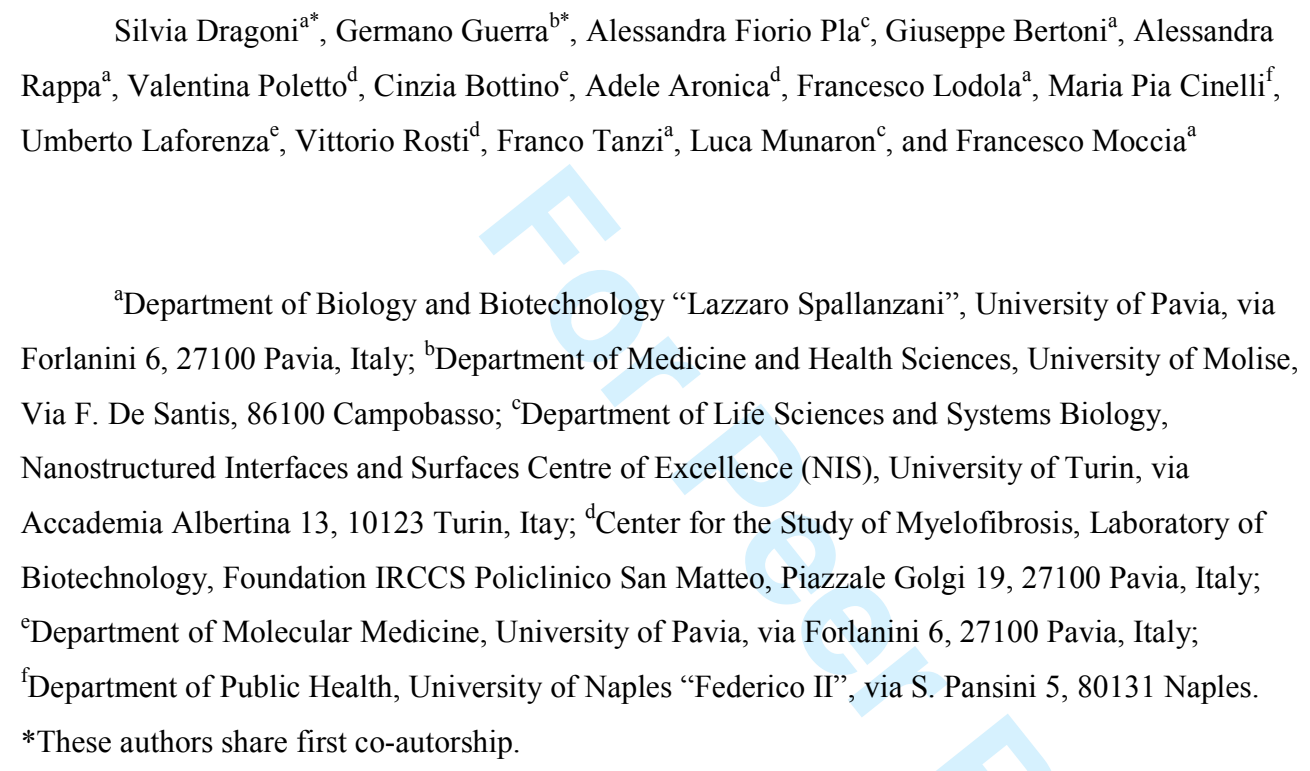

Silvia Dragoni ${ }^{\mathrm{a}^{*}}$, Germano Guerra ${ }^{\mathrm{b} *}$, Alessandra Fiorio Pla ${ }^{\mathrm{c}}$, Giuseppe Bertoni ${ }^{\mathrm{a}}$, Alessandra Rappa $^{\mathrm{a}}$, Valentina Poletto ${ }^{\mathrm{d}}$, Cinzia Bottino ${ }^{\mathrm{e}}$, Adele Aronica ${ }^{\mathrm{d}}$, Francesco Lodola ${ }^{\mathrm{a}}$, Maria Pia Cinelli ${ }^{\mathrm{f}}$, Umberto Laforenza ${ }^{\mathrm{e}}$, Vittorio Rosti ${ }^{\mathrm{d}}$, Franco Tanzi ${ }^{\mathrm{a}}$, Luca Munaron ${ }^{\mathrm{c}}$, and Francesco Moccia ${ }^{\mathrm{a}}$

${ }^{a}$ Department of Biology and Biotechnology “Lazzaro Spallanzani”, University of Pavia, via Forlanini 6, 27100 Pavia, Italy; ${ }^{b}$ Department of Medicine and Health Sciences, University of Molise, Via F. De Santis, 86100 Campobasso; 'Department of Life Sciences and Systems Biology, Nanostructured Interfaces and Surfaces Centre of Excellence (NIS), University of Turin, via Accademia Albertina 13, 10123 Turin, Itay; ${ }^{\mathrm{d} C e n t e r ~ f o r ~ t h e ~ S t u d y ~ o f ~ M y e l o f i b r o s i s, ~ L a b o r a t o r y ~ o f ~}$ Biotechnology, Foundation IRCCS Policlinico San Matteo, Piazzale Golgi 19, 27100 Pavia, Italy; ${ }^{\mathrm{e}}$ Department of Molecular Medicine, University of Pavia, via Forlanini 6, 27100 Pavia, Italy; ${ }^{\mathrm{f}}$ Department of Public Health, University of Naples "Federico II", via S. Pansini 5, 80131 Naples.

*These authors share first co-autorship.

Corresponding author:

Dr. Francesco Moccia

Laboratory of General Physiology,

Department of Biology and Biotechnology "L. Spallanzani”,

University of Pavia,

Via Forlanini 6, 27100, Pavia, Italy.

Tel: 00390382987169

Fax: 00390382987527

E-mail: francesco.moccia@unipv.it

Running head: TRPV4 expression in EPCs

Keywords: Endothelial progenitor cells, TRPV4, phorbol esters, GSK1016790A, RN-1734,

ruthenium red, proliferation

6 figures 


\section{ABSTRACT}

Endothelial progenitor cells (EPCs) are mobilized into circulation to replace damaged endothelial and recapitulate the vascular network of injured tissues. Intracellular $\mathrm{Ca}^{2+}$ signals are key to EPC activation, but it is yet to be elucidated whether they are endowed with the same blend of $\mathrm{Ca}^{2+}$ permeable channels expressed by mature endothelial cells. For instance, endothelial colony forming cells (ECFCs), the only EPC subset truly committed to acquire a mature endothelial phenotype, lack canonical transient receptor potential channels 3, 5 and 6 (TRPC3, 5 and 6), which are widely distributed in vascular endothelium; on the other hand, they express a functional store-operated $\mathrm{Ca}^{2+}$ entry (SOCE). The present study was undertaken to assess whether human circulating EPCs possess TRP vanilloid channel 4 (TRPV4), which plays a master signalling role in mature endothelium, by controlling both vascular remodelling and arterial pressure. We found that EPCs express both TRPV4 mRNA and protein. Moreover, both GSK1016790A (GSK) and phorbol myristate acetate and, two widely employed TRPV4 agonists, induced intracellular $\mathrm{Ca}^{2+}$ signals uniquely in presence of extracellular $\mathrm{Ca}^{2+}$. GSK- and PMA-induced $\mathrm{Ca}^{2+}$ elevations were inhibited by $\mathrm{RN}-1734$ and ruthenium red, which selectively target TRPV4 in mature endothelium. However, TRPV4 stimulation with GSK did not cause EPC proliferation, while the pharmacological blockade of TRPV4 only modestly affected EPC growth in the presence of a growth factor-enriched culture medium. Conversely, SOCE inhibition with BTP-2, $\mathrm{La}^{3+}$ and $\mathrm{Gd}^{3+}$ dramatically decreased cell proliferation. These data indicate that human circulating EPC $\underline{s}$ possess a functional TRPV4 protein before their engraftment into nascent vessels. 


\title{
INTRODUCTION
}

\begin{abstract}
Vascular endothelial cells line the lumen of blood and lymphatic thereby forming a multifunctional signal transduction platform that maintains cardiovascular homeostasis (Mancardi et al., 2011; Moccia et al., 2013b). Endothelial injury is recognized as initial step in the onset of severe cardiovascular diseases, including myocardial infarction, brain stroke, atherosclerosis, and diabetes (Moccia et al., 2010; Moccia et al., 2012a). Endothelial progenitor cells (EPCs) are a sub-population of mononuclear cells (MNCs) which is recruited from either bone marrow (BM) or arterial wall to replace damaged/senescent endothelial cells and recapitulate the vascular network of lesioned organs (Yoder, 2012b). They act by either stimulating local angiogenesis via paracrine signalling or by physically engrafting within neovessels (Yoder, 2012b). It is, therefore, not surprising that circulating EPCs are currently regarded as one of the most promising tools for the cell-based therapy of CV pathologies
\end{abstract} (Alev et al., 2011; Murasawa and Asahara, 2005). Among the different subtypes of EPCs described in the literature (Yoder, 2012a), the so-called endothelial colony forming cells (ECFCs) are unique in their truly belonging to the endothelial lineage and in their ability of forming capillary like structures in vitro and patent vessels in vivo (Basile and Yoder, 2014; Yoder, 2012b). It is, however, largely unknown whether they already express the signal transduction pathways that enable mature endothelial cells to properly respond to external stimuli (Lodola et al., 2012; Moccia et al., 2012c; Moccia et al., 2014b).

An increase in intracellular $\mathrm{Ca}^{2+}$ concentration $\left(\left[\mathrm{Ca}^{2+}\right]_{\mathrm{i}}\right)$ is the earliest response of vascular endothelium to extracellular stimulation (Moccia et al., 2012b; Pla et al., 2012a). The endothelial $\mathrm{Ca}^{2+}$ signals are mainly shaped by the interplay between inositol-1,4,5-trisphosphate ( $\left.\mathrm{InsP}_{3}\right)$-gated $\mathrm{Ca}^{2+}$ release from the endoplasmic reticulum (ER) and $\mathrm{Ca}^{2+}$ influx across the plasma membrane (Moccia et al., 2012b; Moccia et al., 2013b). Store-operated $\mathrm{Ca}^{2+}$ entry (SOCE) sustains a myriad of endothelial 
functions, ranging from cell proliferation to the control of luminal permeability (Abdullaev et al., 2008; Moccia et al., 2012b; Tiruppathi et al., 2006). Recent work from our group has disclosed that a functional SOCE is also present in human circulating EPCs, where it is mediated by the interaction between Stim1, the ER $\mathrm{Ca}^{2+}$ sensor, and Orai1 and canonical transient receptor potential channel 1 (TRPC1), which contribute to the $\mathrm{Ca}^{2+}$-permeable pore-forming domain on the plasma membrane (Lodola et al., 2012; Moccia et al., 2013a; Moccia et al., 2012d; Sánchez-Hernández et al., 2010). Store-dependent $\mathrm{Ca}^{2+}$ inflow controls cell proliferation and in vitro tubulogenesis in EPCs isolated from both peripheral (Dragoni et al., 2011; Dragoni et al., 2014; Lodola et al., 2012) and umbilical cord blood (Dragoni et al., 2013). Conversely, circulating human EPCs lack the diacylglycerol-sensitive canonical transient receptor potential (TRP) channels 3 (TRPC3) and TRPC6, and the polymodal channel TRPC5 (Fiorio Pla and Munaron, 2014; Moccia et al., 2012b; Pla et al., 2012a). This feature is rather surprising when considering the important roles played by these pathways in mature endothelium (Fiorio Pla and Munaron, 2014; Moccia et al., 2012b; Moccia et al., 2014a; Pla et al., 2012a). For instance, TRPC3 and TRPC6 may sustain the pro-angiogenic $\mathrm{Ca}^{2+}$ response to VEGF in microvascular endothelial cells (Cheng et al., 2006; Hamdollah Zadeh et al., 2008). An additional store-independent $\mathrm{Ca}^{2+}$ entry route in mature endothelium is provided by vanilloid TRP channel 4 (TRPV4) (Fiorio Pla and Gkika, 2013; Hatano et al., 2013; Pla et al., 2012a; Schierling et al., 2011; Troidl et al., 2010; Troidl et al., 2009). This is a polymodal TRP channel which acts as a molecular integrator of both chemical and physical stimuli (Earley and Brayden, 2010; Moccia et al., 2012b). Endothelial TRPV4 may be activated by changes in osmotic pressure, fluid shear stress and temperature, by the phorbol derivatives, $4 \alpha$-phorbol-12,13-didecanoate ( $4 \alpha \mathrm{PDD})$ and phorbol myristate acetate (PMA), by arachidonic acid (AA) and its metabolits, and by the specific small molecule agonist, N-((1S)-1-\{[4((2S)-2-\{[(2,4-dichlorophenyl)sulfonyl]amino\}-3-hydroxypropanoyl)-1-piperazinyl $]$ carbonyl $\}$-3methylbutyl)-1-benzothiophene-2-carboxamide (GSK1016790A or GSK) (Baylie and Brayden, 2011; 
Sonkusare et al., 2012; Sullivan et al., 2012). A growing number of studies revealed that TRPV4mediated $\mathrm{Ca}^{2+}$ inflow contributes to endothelial cell proliferation and vascular remodelling (i.e. arteriogenesis) which occurs as a consequence of arterial occlusion in a number of vascular districts (Hatano et al., 2013; Pla et al., 2008; Pla et al., 2012b; Schierling et al., 2011; Troidl et al., 2010; Troidl et al., 2009). Moreover, TRPV4 may regulate arterial pressure by activating a variety of vasodilatory mechanisms, such as nitric oxide (NO), prostaglandin $\mathrm{I}_{2}\left(\mathrm{PGI}_{2}\right)$, and intermediate- and smallconductance $\mathrm{Ca}^{2+}$-activated $\mathrm{K}^{+}$channels $\left(\mathrm{IK}_{\mathrm{Ca}} / \mathrm{SK}_{\mathrm{Ca}}\right)$-mediated endothelial-dependent hyperpolarizing factor (EDHF) (Baylie and Brayden, 2011; Earley and Brayden, 2010). In the light of the key signalling function accomplished by TRPV4 in differentiated endothelial cells, we thus undertook the present investigation to assess whether this $\mathrm{Ca}^{2+}$-permeable route in also expressed in human circulating EPCs. 


\section{MATERIALS AND METHODS}

\section{Cell isolation}

Blood samples $(40 \mathrm{~mL})$ were obtained from healthy human volunteers aged from 22 to 28 years old. The Institutional Review Board at "Istituto di Ricovero e Cura a Carattere Scientifico Policlinico San Matteo Foundation" in Pavia approved all protocols and specifically approved the study. Informed consent was obtained according to the Declaration of Helsinki. Informed written consent was obtained according to the Declaration of Helsinki. We focussed on the so-called endothelial colony forming cells (ECFCs) (Ingram et al., 2004), a subgroup of EPCs which are found in the CD34 $4^{+}$D $45^{-}$fraction of circulating mononuclear cells, exhibit robust proliferative potential and form capillary-like structures in vitro (Ingram et al., 2004; Moccia et al., 2012d). To isolate ECFCs, mononuclear cells (MNCs) were separated from peripheral blood (PB) by density gradient centrifugation on lymphocyte separation medium for $30 \mathrm{~min}$ at $400 \mathrm{~g}$ and washed twice in EBM-2 with $2 \% \mathrm{FCS}$. A median of $36 \times 10^{6} \mathrm{MNCs}$ (range 18-66) were plated on collagen-coated culture dishes (BD Biosciences) in the presence of the endothelial cell growth medium EGM-2 MV Bullet Kit (Lonza) containing endothelial basal medium (EBM-2), 5\% foetal bovine serum, recombinant human (rh) EGF, rhVEGF, rhFGF-B, rhIGF-1, ascorbic acid and heparin, and maintained at $37^{\circ} \mathrm{C}$ in $5 \% \mathrm{CO}_{2}$ and humidified atmosphere. Discard of non-adherent cells was performed after 2 days; thereafter medium was changed three times a week. The outgrowth of endothelial cells from adherent MNCs was characterized by the formation of a cluster of cobblestone-appearing cells (Sánchez-Hernández et al., 2010). That ECFC-derived colonies belonged to endothelial lineage was confirmed as described in (Sánchez-Hernández et al., 2010) and (Lodola et al., 2012). Adult human dermal microvascular endothelial cells (HMVEC-d) and adult human cardiac microvascular endothelial cells (HMVEC-c) were purchased from Lonza and grown in EGM2-MV medium. Cells were used at passages 3-10. 


\section{Solutions}

Physiological salt solution (PSS) had the following composition (in $\mathrm{mM}$ ): $150 \mathrm{NaCl}, 6 \mathrm{KCl}, 1.5$ $\mathrm{CaCl}_{2}, 1 \mathrm{MgCl}_{2}, 10$ Glucose, 10 Hepes. In $\mathrm{Ca}^{2+}$-free solution $\left(0 \mathrm{Ca}^{2+}\right), \mathrm{Ca}^{2+}$ was substituted with $2 \mathrm{mM}$ $\mathrm{NaCl}$, and $0.5 \mathrm{mM}$ EGTA was added. Solutions were titrated to $\mathrm{pH} 7.4$ with $\mathrm{NaOH}$. The osmolality of the extracellular solution, as measured with an osmometer (Wescor 5500, Logan, UT), was 300-310 $\mathrm{mmol} / \mathrm{kg}$.

\section{$\left[\mathrm{Ca}^{2+}\right]_{i}$ measurements and statistics}

EPCs were loaded with $4 \mu \mathrm{M}$ fura-2 acetoxymethyl ester (fura-2/AM; $1 \mathrm{mM}$ stock in dimethyl sulfoxide) in PSS for 1 hour at room temperature. The $\mathrm{Ca}^{2+}$ measuring system has been extensively described in (Berra-Romani et al., 2013; Di Buduo et al., 2014). The $\mathrm{Ca}^{2+}$ fluorochrome has been excited at 340 and $380 \mathrm{~nm}$ and the light emitted detected at $510 \mathrm{~nm} .\left[\mathrm{Ca}^{2+}\right]_{\mathrm{i}}$ was monitored by measuring, for each ROI, the ratio of the mean fluorescence emitted at $510 \mathrm{~nm}$ when exciting alternatively at 340 and $380 \mathrm{~nm}$ (shortly termed "ratio"). An increase in $\left[\mathrm{Ca}^{2+}\right]_{\mathrm{i}}$ causes an increase in the ratio (Berra-Romani et al., 2013; Di Buduo et al., 2014). Ratio measurements were performed and plotted on-line every $3 \mathrm{~s}$. The experiments were performed at room temperature $\left(22^{\circ} \mathrm{C}\right)$. All the data have been collected from ECFCs isolated from the peripheral blood of at least three healthy volunteers. The amplitude of the peak $\mathrm{Ca}^{2+}$ response was measured as the difference between the ratio at the peak and the mean ratio of $1 \mathrm{~min}$ baseline before the peak. Pooled data are given as mean $\pm \mathrm{SE}$ and statistical significance $(P<0.05)$ was evaluated by the Student's $t$-test for unpaired observations.

\section{$R N A$ isolation and RT-PCR}


Total RNA was extracted from the ECFCs using the QIAzol Lysis Reagent (QIAGEN, Italy). Single cDNA was synthesized from RNA ( $1 \mu \mathrm{g})$ using random hexamers and M-MLV Reverse Transcriptase (Invitrogen S.R.L., Italy). Reverse transcription was always performed in the presence or absence (negative control) of the reverse transcriptase enzyme. PCR was performed as previously described by using specific primers (intron-spanning primers) designed for human TRPV4 (sense, 5'TCCAGCTGCTCTACTTCATC-3'; antisense, 5'-CTGAAGCGTAGCCGATCAT -3') and TRPV1 (sense, 5'-AGCTACTACAAGGGCCAGACA-3'; antisense, 5'-AACTTCACGATGCCCAGCTGG3’) (Lodola et al., 2012; Sánchez-Hernández et al., 2010). The RT-PCR reactions were normalized using $\beta$-actin as housekeeping gene (primers used:Hs_ACTB_1_SG, QuantiTect Primer Assay QT00095431, Qiagen). First, the sequence of the TRPV4 band was checked by using the Big dye terminator cycle sequencing kit (Applied Biosystem, PE, USA). PCR products were separated with agarose gel electrophoresis, stained with ethidium bromide, and acquired with the Image Master VDS (Amersham Biosciences Europe, Italy). The molecular weight of the PCR products was compared to the DNA molecular weight marker VIII (Roche Molecular Biochemicals, Italy).

\section{Protein extraction and Western blot analysis}

Protein extraction and Western blot analysis were carried out as described previously (Lodola et al., 2012; Sánchez-Hernández et al., 2010). The anti-TRPV4 antibody was raised against the peptide CDGHQQGYAPKWRAEDAPL in rabbits (Loftstrand Labs). The resulting rabbit serum was then affinity purified to obtain the anti-TRPV4 antibody. The specific controls were performed as previously described (Pla et al., 2012b).

\section{Proliferation assay}


A total of $1 \times 10^{5}$ ECFC-derived cells $\left(1^{\text {st }}\right.$ passage $)$ were plated in $30-\mathrm{mm}$ collagen-treated dishes in endothelial basal medium (EBM-2; Lonza) supplemented with 5\% foetal bovine serum (FBS) in the presence of $20 \mathrm{nM} \mathrm{GSK}$. As a control experiment, cells were seeded in the presence of in the presence of the endothelial cell growth medium EGM-2 MV Bullet Kit (Lonza) containing EBM-2, 5\% FBS, recombinant human (rh) EGF, rhVEGF, rhFGF-B, rhIGF-1, ascorbic acid and heparin. Cultures were incubated at $37^{\circ} \mathrm{C}, 5 \% \mathrm{CO}_{2}$ and cell growth assessed every day until confluence was reached in the control dishes. Cells were then recovered by trypsinization and their number assessed by counting in a hemocytometer. The percentage of growth stimulation was calculated by dividing the total number of cells obtained in presence of GSK by the number of cells in control experiments (i.e. EGM-2 MV) and multiplying the ratio by 100 . The effect of VEGF was evaluated by plating the cells with $10 \mathrm{ng} / \mathrm{ml}$ VEGF and with or without BAPTA $(30 \mu \mathrm{M})$, a membrane-permeable intracellular $\mathrm{Ca}^{2+}$ buffer (Dragoni et al., 2011; Dragoni et al., 2013). Alternatively, 1 x 10 ECFC-derived cells were plated in 30-mm collagen-treated dishes in EGM-2 MV Bullet Kit in the absence (control) and presence of either RN$1734(20 \mu \mathrm{M})$ or ruthenium red $(10 \mu \mathrm{M})$, two well known TRPV4 inhibitors. The effect of TRPV4 blockade on EPC proliferation was evaluated as illustrated above.

\section{Chemicals}

EBM and EGM-2 were purchased from Clonetics (Cell System, St. Katharinen, Germany). Fura-2/AM was obtained from Molecular Probes (Molecular Probes Europe BV, Leiden, The Netherlands). GSK has been synthesized as described in (Zaninetti et al., 2011). All other chemicals were obtained from Sigma Chemical Co. (St. Louis, MO, USA). 


\section{RESULTS}

\section{TRPV4 is expressed in human endothelial colony forming cells}

The expression of TRPV4 mRNA in human EPCs was assessed by RT-PCR. Figure 1A depicts the results of agarose gel electrophoresis of representative PCR reaction products. Single bands of the expected size of cDNA fragments were amplified (246 and $146 \mathrm{bp}$ for TRPV4 and $\beta$-actin, respectively) in isolated cells. In the absence of RT, no PCR-amplified products were detected, thereby showing the specificity of the reaction (Fig. 1A). These data are consistent with the presence of TRPV4 mRNA in human EPCs. In order to determine whether TRPV4 is expressed at protein level, we performed a Western Blot analysis by using affinity-purified antibodies, which revealed a prominent band at $70 \mathrm{kDa}$ (Fig. 1B, right). As a control, we utilized human dermal (HMVEC-d) and coronary (HMVEC-c) microvascular endothelial cells, which both display a protein of the same molecular size (Fig. 1B, left). Therefore, TRPV4 is present at both mRNA and protein level in circulating EPCs.

\section{TRPV4 agonists elicit intracellular $\mathrm{Ca}^{2+}$ signals in endothelial colony forming cells}

In order to assess whether these TRPV4 proteins conduct extracellular $\mathrm{Ca}^{2+}$, EPCs were loaded with Fura-2 and exposed to GSK $(20 \mathrm{nM})$ or PMA $(10 \mu \mathrm{M})$, two specific TRPV4 agonists (Everaerts et al., 2010). As a consequence, GSK has been extensively utilized to assess the biological outcomes of TRPV4 activation in vascular endothelium (Mergler et al., 2011; Sonkusare et al., 2012; Sullivan et al., 2012). Figure $2 \mathrm{~A}$ shows that GSK evoked a transient increase in $\left[\mathrm{Ca}^{2+}\right]_{\mathrm{i}}$ in 121 out of $125(96.8 \%)$ circulating EPCs: the magnitude of the $\mathrm{Ca}^{2+}$ signal was $0.075 \pm 0.005(\mathrm{n}=121)$, whereas the average lag time between the exposition to the agonist and the onset of the response was $46.7 \pm 1.2 \mathrm{sec}(\mathrm{n}=121)$. GSK-induced $\mathrm{Ca}^{2+}$ signals were reversibly prevented by removal of extracellular $\mathrm{Ca}^{2+}$ (Fig. 2B) and by RN-1734 (20 $\mu \mathrm{M}$; n=117) (Fig. 2C), a selective TRPV4 antagonist (Bagher et al., 2012; Zheng et al., 


\section{Page 11 of 34}

2013). Ruthenium red (RR) has also been used as a pharmacological tool to validate TRPV4 expression in vascular endothelium (Hatano et al., 2013; Willette et al., 2008; Zheng et al., 2013). As expected, the $\mathrm{Ca}^{2+}$ response to GSK was reversibly suppressed by pre-incubating the cells with this compound (10 $\mu \mathrm{M} ; \mathrm{n}=104)$ (Fig. 2D).

Subsequently, we probed the effect of PMA, a structurally distinct TRPV4 agonist (Everaerts et al., 2010). Figure $3 \mathrm{~A}$ shows that PMA $(10 \mu \mathrm{M})$ elicited a rapid and monophasic increase in $\left[\mathrm{Ca}^{2+}\right]_{\mathrm{i}}$ in 251 out of 306 EPCs $(82 \%)$. The amplitude of the $\mathrm{Ca}^{2+}$ peak was $0.125 \pm 0.007(\mathrm{n}=251)$, while the latency of the signal ranged between $10 \mathrm{sec}$ and $430 \mathrm{sec}$, the average value being $107.8 \pm 78.9 \mathrm{sec}$ $(n=184)$. PMA-evoked increase in $\left[\mathrm{Ca}^{2+}\right]_{i}$ was reversible (Fig. 3B) and disappeared in absence of extracellular $\mathrm{Ca}^{2+}$ (Fig. 3C). Notably, readmission of $\mathrm{Ca}^{2+}$ to the bathing solution always restored the $\left[\mathrm{Ca}^{2+}\right]_{\mathrm{i}}$ raise (Fig. 2C), as well as removal of extracellular $\mathrm{Ca}^{2+}$ caused the rapid decline of the $\left[\mathrm{Ca}^{2+}\right]_{\mathrm{i}}$ elevation to the baseline (Fig. 3D). Similar to GSK, both RN-1734 (20 $\mu$ M; n=102) (Fig. 3E) and RR $(10 \mu \mathrm{M} ; \mathrm{n}=170)$ (Fig. 3F) abrogated PMA-evoked $\mathrm{Ca}^{2+}$ signals in human EPCs. Consistent with these results, the acute application of $\mathrm{RR}(10 \mu \mathrm{M})$ abrogated the $\mathrm{Ca}^{2+}$ response to PMA in 53 out of 53 (100\%) cells (Fig. 3G). Phorbol esters might also stimulate TRPV1 channels (Baylie and Brayden, 2011), whose transcripts are expressed in circulating EPCs (see Fig. S1). However, PMA-induced $\mathrm{Ca}^{2+}$ signals were unaffected by capsazepine $(10 \mu \mathrm{M})($ Fig. 3H), a specific TRPV1 inhibitor. This result strongly hints at TRPV4 as the molecular target of PMA. Overall, the pharmacological profile (i.e. activation by phorbol esters and GSK, and blockade by RN-1734 and RR) herein described concurs with that reported in mature human endothelium, at both micro- and macrovascular level (Bubolz et al., 2012a; Hatano et al., 2013; Pla et al., 2008; Pla et al., 2012b; Sonkusare et al., 2012; Sullivan et al., 2012), and demonstrate that the TRPV4 protein detected by immunoblotting serves as a $\mathrm{Ca}^{2+}$ permeable membrane channel in human EPCs. Conversely, neither hypotonic stimulation ( $\mathrm{n}=141$ ) (Fig. 4A) or 1-2 $\mu \mathrm{M}$ arachidonic acid (AA) (n=102) (Fig. 4B), which have been associated to TRPV4- 
mediated $\mathrm{Ca}^{2+}$ inflow in mature endothelium (Moccia et al., 2012b; Pla et al., 2008), ignited any detectable increase in $\left[\mathrm{Ca}^{2+}\right]_{\mathrm{i}}$ in EPCs responsive to $20 \mathrm{nM}$ GSK.

\section{TRPV4-induced $\mathrm{Ca}^{2+}$ inflow is not amplified by intracellular $\mathrm{Ca}^{2+}$ release in EPCs}

Extracellular $\mathrm{Ca}^{2+}$ influx gated through TRPV4 channels may be further amplified by the mechanism of $\mathrm{Ca}^{2+}$-induced $\mathrm{Ca}^{2+}$ release $(\mathrm{CICR})$, thereby resulting in a massive $\mathrm{Ca}^{2+}$ mobilization from the intracellular $\mathrm{Ca}^{2+}$ pool. For instance, TRPV4-gated $\mathrm{Ca}^{2+}$ influx recruits $\mathrm{InsP}_{3}$-dependent $\mathrm{Ca}^{2+}$ release and triggers propagating $\mathrm{Ca}^{2+}$ oscillations in mouse astrocyte endfeet (Dunn et al., 2013). We have widely established that the $\mathrm{ER} \mathrm{Ca}^{2+}$ content in human EPCs is mainly sensitive to $\mathrm{InsP}_{3}$ dependent stimulation, while functional ryanodine receptors seem to be absent (Dragoni et al., 2011; Dragoni et al., 2013; Lodola et al., 2012; Sánchez-Hernández et al., 2010). In order to assess the contribution of the endogenous $\mathrm{Ca}^{2+}$ reservoir to TRPV4-induced $\mathrm{Ca}^{2+}$ signals, we depleted the $\mathrm{InsP}_{3}$ regulated $\mathrm{Ca}^{2+}$ pool with cyclopiazonic acid (CPA). CPA is a selective inhibitor of Sarco-Endoplasmic Reticulum $\mathrm{Ca}^{2+}$-ATPase (SERCA) activity which impairs ER $\mathrm{Ca}^{2+}$ storage ability. The application of CPA $(10 \mu \mathrm{M})$ in the presence of extracellular $\mathrm{Ca}^{2+}$ led to an initial increase in $\left[\mathrm{Ca}^{2+}\right]_{\mathrm{i}}$ due to interruption of the ER $\mathrm{Ca}^{2+}$ cycle between SERCA-mediated $\mathrm{Ca}^{2+}$ re-uptake and $\mathrm{Ca}^{2+}$ efflux through ER leakage channels. The following decay of the intracellular $\mathrm{Ca}^{2+}$ peak to a plateau level was due to SOCE activation following depletion of the intracellular $\mathrm{Ca}^{2+}$ reserve (Lodola et al., 2012; SánchezHernández et al., 2010). Thirty minutes of pre-treatment with $10 \mu \mathrm{M}$ CPA have been shown to fully empty the $\mathrm{InsP}_{3}$-sensitive $\mathrm{Ca}^{2+}$ store in human EPCs (Dragoni et al., 2011; Sánchez-Hernández et al., 2010). However, the subsequent addition of GSK $(20 \mathrm{nM})$ caused an increase in $\left[\mathrm{Ca}^{2+}\right]_{\mathrm{i}}$ which did not significantly $(\mathrm{p}<0.05)$ differ from that observed in untreated cells (Fig. 5A-C). In order to confirm this data, we challenged with GSK $(20 \mathrm{nM})$ EPCs pre-incubated with 2-APB $(50 \mu \mathrm{M})$, a popular $\operatorname{InsP}_{3} \mathrm{R}$ 
inhibitor (Dragoni et al., 2011; Dragoni et al., 2013). In according with our previous results, 2-APB did not significantly $(\mathrm{p}<0.05)$ affect GSK-induced $\mathrm{Ca}^{2+}$ signals in EPCs (Fig. 5E-F).

\section{Effect of TRPV4-mediated $\mathrm{Ca}^{2+}$ entry on EPC proliferation}

TRPV4-mediated $\mathrm{Ca}^{2+}$ entry promotes cell replication in a variety of mature endothelial cells (Hatano et al., 2013; Pla et al., 2008; Schierling et al., 2011; Troidl et al., 2010; Troidl et al., 2009). Therefore, we focussed on EPC proliferation to evaluate the physiological outcome of TRPV4 activation. Surprisinly, TRPV4 stimulation with GSK did not cause a statistically relevant $(\mathrm{p}<0.05)$ increase in cell number, when EPCs were grown in a basal medium devoid of growth factors and supplemented with $5 \%$ foetal bovine serum (Figure 6A). Our control experiments demonstrated that EPC proliferation occurs in a $\mathrm{Ca}^{2+}$-dependent manner when the cells are stimulated with VEGF (10 ng/ml), as previously reported by our group (Fig. 6B) (Dragoni et al., 2011; Dragoni et al., 2013; Lodola et al., 2012; Sánchez-Hernández et al., 2010). Therefore, TRPV4 activation by GSK does not lead to cell replication in endothelial committed progenitors. We then sought to assess whether TRPV4 sustains EPC proliferation during EPC expansion with the EGM-2 MV Bullet Kit. Figure 6C shows that $\mathrm{RR}(10 \mu \mathrm{M})$ and $\mathrm{RN}-1734(20 \mu \mathrm{M})$ cause a modest inhibition in cell growth when compared to the dramatic effect exerted by BTP-2 $(20 \mu \mathrm{M})$, a selective inhibitor of SOCE in EPCs (Lodola et al., 2012; Moccia et al., 2012d; Moccia et al., 2014a; Sánchez-Hernández et al., 2010). However, BTP-2 has been shown to affects conductances other than Orai1 and TRPC1 in other cellular settings (Moccia et al., 2012d; Moccia et al., 2014a). Therefore, we confirmed this result by showing that low micromolar doses of $\mathrm{La}^{3+}$ and $\mathrm{Gd}^{3+}$, which selectively interfere with SOCE at this concentration (Moccia et al., 2012d; Moccia et al., 2014a), dramatically reduced cell proliferation (Fig. 6C), as previously shown by our group in healthy EPCs (Lodola et al., 2012). These data are consistent with those we have previously described in both normal cells and EPCs isolated from RCC patients (Lodola et al., 2012; 
2

3

4

5

6

7

8

9

10

11

12

13

14

15

16

17

18

19

20

21

22

23

24

25

26

27

28

29

30

31

32

33

34

35

36

37

38

39

40

41

42

43

44

45

46

47

48

49

50

51

52

53

54

55

56

57

58

59

60

Sánchez-Hernández et al., 2010): overall, they strongly suggest that SOCE is more powerful in delivering pro-angiogenic $\mathrm{Ca}^{2+}$ signals to human EPCs than TRPV4.

John Wiley \& Sons, Inc. 


\section{DISCUSSION}

TRPV4 has recently been shown to promote mature EC proliferation both in vitro and in vivo due to the activation of a host of $\mathrm{Ca}^{2+}$-dependent transcription factors, such as nuclear factor of activated T-cells, calcineurin-dependent 1 (NFATc1), Kv channel interacting protein 3, calsenilin (KCNIP3/CSEN/DREAM), and myocyte enhancer factor 2C (MEF2C). Moreover, TRPV4-mediated $\mathrm{Ca}^{2+}$ inflow drives TECs to both migrate and replicate, a feature which hints at this channel as a suitable target for alternative anti-angiogenic strategies. Apart from the classic process of sprouting angiogenesis, tumour vascularization may require the contribution of bone marrow-derived EPCs (Gao et al., 2009; Moccia et al., 2014a). We have recently suggested that the pharmacological blockade of extracellular $\mathrm{Ca}^{2+}$ inflow might be successfully employed in anti-cancer strategies when the target channel is present both in mature ECs and in more immature committed progenitors (Moccia et al., 2014a). Therefore, we endeavoured the present investigation to assess whether TRPV4 is expressed and controls proliferation in peripheral EPC, the only EPC subset truly belonging to the endothelial lineage and to physically engraft within neovessels in vivo.

\section{A functional TRPV4 is expressed in human EPCs}

We provided the evidence that TRPV4 is present in circulating human EPCs at both mRNA and protein level. Immunoblotting detected a single band at $70 \mathrm{kDa}$, which is in the same range as that reported in human microvascular endothelium (Pla et al., 2012b). Conversely, human coronary ECs were recently found to express two TRPV4 bands at 110 and $98 \mathrm{kDa}$, respectively (Bubolz et al., 2012b). In this regard, immunoblotting conducted in both kidney extracts (Liedtke and Friedman, 2003) and rat cholangiocytes (Gradilone et al., 2007) revealed a double band pattern: the $107 \mathrm{kDa}$ protein and a shorter $75 \mathrm{kDa}$ isoform. The lower molecular band observed in both EPCs and 
microvascular ECs might, therefore, be attributed to an alternative splice variant or to post-translational modifications of TRPV4. For instance, the anti-TRPV4 immunoblot showed only the $75 \mathrm{kDa}$ band when rat cholangiocyte homogenates were treated with N-glycosidase (Gradilone et al., 2007). These results indicate that, unlike TRPC3, TRPC5 and TRPC6, TRPV4 is expressed by EPCs before they engraft within the foci of neovascularisation. It is, however, likely that specific environmental cues instruct EPCs to promote TRPV4 glycosylation when they acquire a macrovascular endothelial phenotype (Aird, 2012). The expression of a functional TRPV4 protein in EPCs has then been demonstrated by the $\mathrm{Ca}^{2+}$ signals occurring in response to two structurally distinct TRPV4 agonists, namely PMA and GSK. Accordingly, both PMA- and GSK-evoked elevations in $\left[\mathrm{Ca}^{2+}\right]_{\mathrm{i}}$ have been observed in the presence, but not in the absence, of extracellular $\mathrm{Ca}^{2+}$ and are inhibited by both RR, which is an unselective TRPV inhibitor, and RN 1734, which specifically blocks TRPV4. The kinetics of the $\mathrm{Ca}^{2+}$ response to PMA and GSK are, however, different. Both compounds have widely been employed to assess the expression of a conductive TRPV4 channel in mature ECs both in vitro and in vivo (Hatano et al., 2013; Schierling et al., 2011; Troidl et al., 2010; Troidl et al., 2009). Phorbol esters activate TRPV4 independently on protein kinase $C$, i.e. by physically interacting with a binding pocket located within the transmembrane III-IV region of the channel protein (Everaerts et al., 2010). Conversely, the activating mechanism of GSK is yet to be elucidated. Unlike PMA, the $\mathrm{Ca}^{2+}$ response to GSK is transient and rapidly decays to the baseline. The rapid recovery of intracellular $\mathrm{Ca}^{2+}$ in the continuous presence of the agonist might be due to GSK-induced channel desensitization, as recently described in (Jin et al., 2011). These authors demonstrated that GSK specifically activates TRPV4gated $\mathrm{Ca}^{2+}$ inflow, thereafter causing a rapid down-regulation of the plasmalemmal protein that is associated to the shut-down of channel activity (Jin et al., 2011). This feature, however, does not apply to each vascular district, as human corneal endothelial cells display a sustained increase in $\left[\mathrm{Ca}^{2+}\right]_{\mathrm{i}}$ even upon agonist washout (Mergler et al., 2011). As compared to PMA, however, the onset of GSK- 
induced $\mathrm{Ca}^{2+}$ signals is relatively fast. The long delay before the development of the $\mathrm{Ca}^{2+}$ response to phorbol esters is a well documented hallmark of TRPV4 signalling (Nilius et al., 2004), and has been reported both in micro- and macrovascular endothelial cells (Bubolz et al., 2012a; Pla et al., 2012b). This feature is related to the dynamics of actin cytoskeleton: arachidonic acid (AA)-induced actin polymerization dramatically reduces the latency distribution of the $\mathrm{Ca}^{2+}$ response to $4 \alpha \mathrm{PDD}$ in breast tumour-derived endothelial cells (Pla et al., 2012b). Future experiments will have to assess this mechanism also in EPCs.

Hypotonic cell swelling and arachidonic acid do not stimulate TRPV4-mediated $\mathrm{Ca}^{2+}$ entry in EPCs

TRPV4 is a polymodal channel that may be also activated by mechanical stimulation and endogenous second messengers, such as AA and its metabolites, including epoxyeicosatrienoic acids (EETs) (Everaerts et al., 2010; Moccia et al., 2012b). For instance, a hypotonic challenge has been shown to produce TRPV4-mediated $\mathrm{Ca}^{2+}$ signals in human corneal endothelial cells and carotid artery endothelial cells (Hartmannsgruber et al., 2007). Similarly, low micromolar doses of AA recruit TRPV4 in mouse aortic endothelial cells (Vriens et al., 2004), human coronary ECs (Zheng et al., 2013) and in B-TECs (Pla et al., 2012b). However, both hypotonic stimulation and low $\mu \mathrm{M}$ doses of AA failed to induce intracellular $\mathrm{Ca}^{2+}$ signals in GSK-sensitive EPCs. These results imply a difference in the gating mechanism between mature endothelial cells and their committed progenitors. It has been suggested that AA and its metabolites bind to a LSRKFKD domain, that is homolog to the archidonate recognition sequence (ARS) of melastatin TRPM2 (TRPM2) (ISXXTKE) (Everaerts et al., 2010). Alternatively, TRPV4 stimulation by either cell swelling or low $\mu \mathrm{M}$ concentrations of AA may activate $\mathrm{Ca}^{2+}$ entry at a lower extent as compared to GSK and PMA, thereby caused a sub-membranal $\mathrm{Ca}^{2+}$ elevation that is missed by our $\mathrm{Ca}^{2+}$ imaging system. Whatever its molecular underpinnings, the lack of 
$\mathrm{a} \mathrm{Ca}^{2+}$ response to AA explains EPC insensitivity to hypotonic stress; accordingly, cell swelling elicits TRPV4-mediated $\mathrm{Ca}^{2+}$ influx by stimulating phospholipase A2 (PLA2) to produce AA, which is in turn metabolized by P450 epoxyoxidases to epoxyeicosatrienoic acids (Everaerts et al., 2010). Thus, if AA fails to evoke a detectable increase in $\left[\mathrm{Ca}^{2+}\right]_{\mathrm{i}}$, neither hypotonic challenge is expected to augment intracellular $\mathrm{Ca}^{2+}$ levels.

\section{Intracellular $\mathrm{Ca}^{2+}$ mobilization does not sustain TRPV4-mediated $\mathrm{Ca}^{2+}$ inflow}

We have recently shown that EPCs may utilize extracellular $\mathrm{Ca}^{2+}$ influx to stimulate $\mathrm{Ca}^{2+}$ mobilization from the $\mathrm{InsP}_{3}$-sensitive intracellular $\mathrm{Ca}^{2+}$ pool. For instance, in umbilical cord derivedEPCs, TRPC3 gates an influx of $\mathrm{Ca}^{2+}$ which subsequently promotes $\mathrm{InsP}_{3}$-dependent $\mathrm{Ca}^{2+}$ release (Dragoni et al., 2013). However, the depletion of $\mathrm{ER} \mathrm{Ca}^{2+}$ pool does not affect the $\mathrm{Ca}^{2+}$ response to GSK in their peripheral counterparts. Similarly, the pharmacological inhibition of $\operatorname{Ins}_{3} \mathrm{Rs}$ does not imparir TRPV4-evoked $\mathrm{Ca}^{2+}$ signalling in circulating EPCs. This result concurs with the findings reported in endothelial cells of mouse mesenteric arteries (Sonkusare et al., 2012), where TRPV4induced $\mathrm{Ca}^{2+}$ inflow is an event temporally and spatially distinct from $\mathrm{InsP}_{3}$-dependent $\mathrm{Ca}^{2+}$ release, but not with those described in mouse astrocytes (Dunn et al., 2013). Perivascular astrocytic endfeet generate intracellular $\mathrm{Ca}^{2+}$ waves by impinging on the dynamic synergy between TRPV4-mediated $\mathrm{Ca}^{2+}$ entry and $\mathrm{InsP}_{3}$-evoked $\mathrm{Ca}^{2+}$ release: these propagated $\mathrm{Ca}^{2+}$ elevations are abrogated by superfusing the cells with either CPA or xestospongin $\mathrm{C}$, a well known $\operatorname{Ins}_{3} \mathrm{R}$ inhibitor. Another observation suggests that TRPV4 channels on the plasma membrane are uncoupled from the intracellular $\mathrm{Ca}^{2+}$ releasing machinery sitting on the underlying ER membranes. TRPV4 activity is potentiated by a modest increase $\mathrm{Ca}^{2+}$ levels in close proximity of the inner mouth of the channel pore, while it is inhibited by higher $\mathrm{Ca}^{2+}$ elevations (Everaerts et al., 2010). Conversely, the global elevation in $\left[\mathrm{Ca}^{2+}\right]_{\mathrm{i}}$ elicited by SERCA inhibition does not interfere with TRPV4-dependent $\mathrm{Ca}^{2+}$ inflow in EPCs. 
This feature suggests that this massive $\left[\mathrm{Ca}^{2+}\right]_{\mathrm{i}}$ raise is not translated into a change in $\mathrm{Ca}^{2+}$ concentration in vicinity of the $\mathrm{COOH}$-terminal calmodulin-binding site of TRPV4 protein, which senses the changes in environmental $\mathrm{Ca}^{2+}$.

\section{TRPV4 plays a minor role in controlling EPC proliferation}

TRPV4-mediated $\mathrm{Ca}^{2+}$ inflow has long been known to control endothelial proliferation and vascular remodelling due to the activation of several $\mathrm{Ca}^{2+}$-dependent transcription factors, such as nuclear factor of activated T-cells, cytoplasmic, calcineurin-dependent 1 (NFATc1), Kv channel interacting protein 3, calsenilin (KCNIP3/CSEN/DREAM), and myocyte enhancer factor 2C (MEF2C) (Hatano et al., 2013; Pla et al., 2008; Pla et al., 2012b; Schierling et al., 2011; Thodeti et al., 2009; Troidl et al., 2010; Troidl et al., 2009). For instance, TRPV4-dependent $\mathrm{Ca}^{2+}$ signals drive the shear stress- and $4 \alpha \mathrm{PDD}$-induced growth of collateral vessels (arteriogenesis) which occurs as a consequence of arterial occlusion in a number of vascular districts (Schierling et al., 2011; Troidl et al., 2010; Troidl et al., 2009). In addition, TRPV4-induced $\mathrm{Ca}^{2+}$ entry promotes proliferation of human brain capillary endothelial cells (Hatano et al., 2013) and of breast tumour-derived endothelial cells (B-TECs) (Pla et al., 2008; Pla et al., 2012b). However, selective stimulation of TRPV4 with GSK did not promote EPC growth when the cells were plated in the absence of any further growth factor. These results are different from those reported in human brain capillary endothelial cells and in B-TECs, which are induced to replicate when TRPV4 is stimulated with $4 \alpha \mathrm{PDD}$ and AA, respectively (Hatano et al., 2013; Pla et al., 2008). Likewise, endothelial cells are prompted to undergo mitosis upon in vivo application of $4 \alpha$ PDD in rat carotid artery (Schierling et al., 2011), rabbit femoral artery (Troidl et al., 2009), and pig limb arteries (Troidl et al., 2010). Therefore, TRPV4-gated $\mathrm{Ca}^{2+}$ inflow per se does not entail EPC proliferation and is likely to require the concomitant activation of additional $\mathrm{Ca}^{2+}$ entry pathways or signal transduction cascades. Consistent with this hypothesis, when the cells were expanded in a culture 
medium supplemented with several growth factors and serum, the pharmacological inhibition of TRPV4 with either RR or RN-1734 only partially reduced EPC proliferation. Interestingly, RR exerted a stronger effect as compared to RN-1374. However, while the latter is a drug designed to selectively impair TRPV4-mediated $\mathrm{Ca}^{2+}$ inflow, the former may affect other TRPV channels. In particular, RR may block TRPV1-gated $\mathrm{Ca}^{2+}$ entry in human corneal endothelial cells (Mergler et al., 2011). It is, therefore, conceivable that the higher extent of inhibition caused by this compound is due to the blockade of a TRPV1-dependent $\mathrm{Ca}^{2+}$ influx. Unlike RR and RN-1734, however, the blockade of SOCE with three structurally distinct inhibitors, i.e. BTP-2, $\mathrm{La}^{3+}$ and $\mathrm{Gd}^{3+}$, fully abrogated cell replication. Therefore, Orai1 and TRPC1 deliver a more powerful pro-angiogenic $\mathrm{Ca} 2+$ stimulus to endothelial committed progenitors as compared to TRPV4. It is tempting to speculate that the $\mathrm{Ca}^{2+}$ sensitive machinery that translates TRPV4-mediated $\mathrm{Ca}^{2+}$ inflow into a mitogenic signal relocates in vicinity to the inner mouth of the channel pore only after EPC engraftment into the vasculature and subsequent acquisition of a mature endothelial phenotype. Alternatively, we might invoke the recent finding that TRPV4 activity is confined to a few sites on the endothelial membrane, even though the channel is evenly distributed along the whole cell surface (Sullivan et al., 2012). In this view, the agonist-dependent recruitment of TRPV4 channels selectively coupled to the decoders of the proliferative stimulus might occur only after full EPC differentiation to endothelial lineage. Yet, future studies will have to unveil whether TRPV4 is already capable of triggering $\mathrm{NO}$ and/or $\mathrm{PGI}_{2}$ synthesis and/or EDHF activation in EPCs as it does in mature endothelium. 


\section{Competing interests \\ None declared.}

John Wiley \& Sons, Inc. 


\section{ACKNOWLEDGMENTS}

We are grateful to Daniele Guido and Marta Reforgiato for their help during the experiments. Dr. Dmitry Lim, University of Eastern Piedmont, Novara, is kindly acknowledged for critical reading and comments to the manuscript. The present article is dedicated to the memory of Giuseppe Bertoni, who passed by on August $30^{\text {th }}, 2011$, at the age of 23 yo. 
Abdullaev IF, Bisaillon JM, Potier M, Gonzalez JC, Motiani RK, Trebak M. 2008. Stim1 and Orai1 mediate CRAC currents and store-operated calcium entry important for endothelial cell proliferation. Circ Res 103(11):1289-1299.

Aird WC. 2012. Endothelial cell heterogeneity. Cold Spring Harbor perspectives in medicine 2(1).

Alev C, Ii M, Asahara T. 2011. Endothelial progenitor cells: a novel tool for the therapy of ischemic diseases. Antioxid Redox Signal 15(4):949-965.

Bagher P, Beleznai T, Kansui Y, Mitchell R, Garland CJ, Dora KA. 2012. Low intravascular pressure activates endothelial cell TRPV4 channels, local $\mathrm{Ca} 2+$ events, and IKCa channels, reducing arteriolar tone. Proc Natl Acad Sci U S A 109(44):18174-18179.

Basile DP, Yoder MC. 2014. Circulating and tissue resident endothelial progenitor cells. J Cell Physiol 229(1):10-16.

Baylie RL, Brayden JE. 2011. TRPV channels and vascular function. Acta Physiol 203(1):99-116.

Berra-Romani R, Avelino-Cruz JE, Raqeeb A, Della Corte A, Cinelli M, Montagnani S, Guerra G, Moccia F, Tanzi F. 2013. Ca2+-dependent nitric oxide release in the injured endothelium of excised rat aorta: a promising mechanism applying in vascular prosthetic devices in aging patients. BMC Surg 13 Suppl 2:S40.

Bubolz AH, Mendoza SA, Zheng X, Zinkevich NS, Li R, Gutterman DD, Zhang DX. 2012a. Activation of endothelial TRPV4 channels mediates flow- induced dilation in human coronary arterioles: role of $\mathrm{Ca} 2+$ entry and mitochondrial ROS signaling. Am J Physiol Heart Circ Physiol 302(3):H634-H642.

Bubolz AH, Mendoza SA, Zheng X, Zinkevich NS, Li R, Gutterman DD, Zhang DX. 2012b. Activation of endothelial TRPV4 channels mediates flow- induced dilation in human coronary arterioles: role of $\mathrm{Ca} 2+$ entry and mitochondrial ROS signaling. American Journal of Physiology-Heart and Circulatory Physiology 302(3):H634-H642.

Cheng HW, James AF, Foster RR, Hancox JC, Bates DO. 2006. VEGF activates receptor-operated cation channels in human microvascular endothelial cells. Arteriosclerosis Thrombosis and Vascular Biology 26(8):1768-1776.

Di Buduo CA, Moccia F, Battiston M, De Marco L, Mazzucato M, Moratti R, Tanzi F, Balduini A. 2014. The importance of calcium in the regulation of megakaryocyte function. Haematologica.

Dragoni S, Laforenza U, Bonetti E, Lodola F, Bottino C, Berra-Romani R, Carlo Bongio G, Cinelli MP, Guerra G, Pedrazzoli P, Rosti V, Tanzi F, Moccia F. 2011. Vascular endothelial growth factor stimulates endothelial colony forming cells proliferation and tubulogenesis by inducing oscillations in intracellular Ca2+ concentration. Stem Cells 29(11):1898-1907.

Dragoni S, Laforenza U, Bonetti E, Lodola F, Bottino C, Guerra G, Borghesi A, Stronati M, Rosti V, Tanzi F, Moccia F. 2013. Canonical transient receptor potential 3 channel triggers vascular endothelial growth factor-induced intracellular $\mathrm{Ca} 2+$ oscillations in endothelial progenitor cells isolated from umbilical cord blood. Stem Cells Dev 22(19):2561-2580.

Dragoni S, Laforenza U, Bonetti E, Reforgiato M, Poletto V, Lodola F, Bottino C, Guido D, Rappa A, Pareek S, Tomasello M, Guarrera MR, Cinelli MP, Aronica A, Guerra G, Barosi G, Tanzi F, Rosti V, Moccia F. 2014. Enhanced Expression of Stim, Orai, and TRPC Transcripts and Proteins in Endothelial Progenitor Cells Isolated from Patients with Primary Myelofibrosis. PLoS One 9(3):e91099.

Dunn KM, Hill-Eubanks DC, Liedtke WB, Nelson MT. 2013. TRPV4 channels stimulate Ca2+induced $\mathrm{Ca} 2+$ release in astrocytic endfeet and amplify neurovascular coupling responses. Proc Natl Acad Sci U S A 110(15):6157-6162. 
Earley S, Brayden JE. 2010. Transient receptor potential channels and vascular function. Clin Sci 119(1-2):19-36.

Everaerts W, Nilius B, Owsianik G. 2010. The vanilloid transient receptor potential channel TRPV4: From structure to disease. Prog Biophys Mol Biol 103(1):2-17.

Fiorio Pla A, Gkika D. 2013. Emerging role of TRP channels in cell migration: from tumor vascularization to metastasis. Front Physiol 4:311.

Fiorio Pla A, Munaron L. 2014. Functional properties of ion channels and transporters in tumour vascularization. Philos Trans R Soc Lond B Biol Sci 369(1638):20130103.

Gao DC, Nolan D, McDonnell K, Vahdat L, Benezra R, Altorki N, Mittal V. 2009. Bone marrowderived endothelial progenitor cells contribute to the angiogenic switch in tumor growth and metastatic progression. Biochim Biophys Acta 1796(1):33-40.

Gradilone SA, Masyuk AI, Splinter PL, Banales JM, Huang BQ, Tietz PS, Masyuk TV, LaRusso NF. 2007. Cholangiocyte cilia express TRPV4 and detect changes in luminal tonicity inducing bicarbonate secretion. Proc Natl Acad Sci U S A 104(48):19138-19143.

Hamdollah Zadeh MA, Glass CA, Magnussen A, Hancox JC, Bates DO. 2008. VEGF-Mediated Elevated Intracellular Calcium and Angiogenesis in Human Microvascular Endothelial Cells In Vitro are Inhibited by Dominant Negative TRPC6. Microcirculation 15(7):605-614.

Hartmannsgruber V, Heyken W-T, Kacik M, Kaistha A, Grgic I, Harteneck C, Liedtke W, Hoyer J, Koehler R. 2007. Arterial Response to Shear Stress Critically Depends on Endothelial TRPV4 Expression. Plos One 2(9).

Hatano N, Suzuki H, Itoh Y, Muraki K. 2013. TRPV4 partially participates in proliferation of human brain capillary endothelial cells. Life Sci 92(4-5):317-324.

Ingram DA, Mead LE, Tanaka H, Meade V, Fenoglio A, Mortell K, Pollok K, Ferkowicz MJ, Gilley D, Yoder MC. 2004. Identification of a novel hierarchy of endothelial progenitor cells using human peripheral and umbilical cord blood. Blood 104(9):2752-2760.

Jin M, Wu Z, Chen L, Jaimes J, Collins D, Walters ET, O'Neil RG. 2011. Determinants of TRPV4 Activity following Selective Activation by Small Molecule Agonist GSK1016790A. Plos One $6(2)$.

Liedtke W, Friedman JM. 2003. Abnormal osmotic regulation in trpv4(-/-) mice. Proc Natl Acad Sci U S A 100(23):13698-13703.

Lodola F, Laforenza U, Bonetti E, Lim D, Dragoni S, Bottino C, Ong HL, Guerra G, Ganini C, Massa M, Manzoni M, Ambudkar IS, Genazzani AA, Rosti V, Pedrazzoli P, Tanzi F, Moccia F, Porta C. 2012. Store-operated $\mathrm{Ca} 2+$ entry is remodelled and controls in vitro angiogenesis in endothelial progenitor cells isolated from tumoral patients. PLoS One 7(9):e42541.

Mancardi D, Pla AF, Moccia F, Tanzi F, Munaron L. 2011. Old and new gasotransmitters in the cardiovascular system: focus on the role of nitric oxide and hydrogen sulfide in endothelial cells and cardiomyocytes. Curr Pharm Biotechnol 12(9):1406-1415.

Mergler S, Valtink M, Taetz K, Sahlmueller M, Fels G, Reinach PS, Engelmann K, Pleyer U. 2011. Characterization of transient receptor potential vanilloid channel 4 (TRPV4) in human corneal endothelial cells. Exp Eye Res 93(5):710-719.

Moccia F, Avelino-Cruz JE, Sanchez-Hernandez Y, Tanzi F. 2010. Ca2+ signalling in damaged endothelium: Do connexin hemichannels aid in filling the gap? Curr Drug Ther 5(4):277-287.

Moccia F, Berra-Romani R, Tanzi F. 2012a. Ca2+ signalling in damaged endothelium and arterial remodelling: Do connexin hemichannels provide a suitable target to prevent in-stent restenosis? Curr Drug Ther 7(4):268-280.

Moccia F, Berra-Romani R, Tanzi F. 2012b. Update on vascular endothelial $\mathrm{Ca}(2+)$ signalling: A tale of ion channels, pumps and transporters. World J Biol Chem 3(7):127-158. 
Moccia F, Bonetti E, Dragoni S, Fontana J, Lodola F, Romani RB, Laforenza U, Rosti V, Tanzi F. 2012c. Hematopoietic Progenitor and Stem Cells Circulate by Surfing on Intracellular Ca2+ Waves: A Novel Target for Cell-based Therapy and Anti-cancer Treatment? Curr Signal Transd T 7(2):161-176.

Moccia F, Dragoni S, Cinelli M, Montagnani S, Amato B, Rosti V, Guerra G, Tanzi F. 2013a. How to utilize $\mathrm{Ca} 2+$ signals to rejuvenate the repairative phenotype of senescent endothelial progenitor cells in elderly patients affected by cardiovascular diseases: a useful therapeutic support of surgical approach? BMC Surg 13 Suppl 2:S46.

Moccia F, Dragoni S, Lodola F, Bonetti E, Bottino C, Guerra G, Laforenza U, Rosti V, Tanzi F. 2012d. Store-dependent $\mathrm{Ca}(2+)$ entry in endothelial progenitor cells as a perspective tool to enhance cell-based therapy and adverse tumour vascularization. Curr Med Chem 19(34):5802-5818.

Moccia F, Dragoni S, Poletto V, Rosti V, Tanzi F, Ganini C, Porta C. 2014a. Orail and Transient Receptor Potential Channels as Novel Molecular Targets to Impair Tumor Neovascularisation in Renal Cell Carcinoma and other Malignancies. Anticancer Agents Med Chem 14(2):296-312.

Moccia F, Lodola F, Dragoni S, Bonetti E, Bottino C, Guerra G, Laforenza U, Rosti V, Tanzi F. 2014b. $\mathrm{Ca} 2+$ signalling in endothelial progenitor cells: a novel means to improve cell-based therapy and impair tumour vascularisation. Curr Vasc Pharmacol 12(1):87-105.

Moccia F, Tanzi F, Munaron L. 2013b. Endothelial Remodelling and Intracellular Calcium Machinery. Curr Mol Med.

Murasawa S, Asahara T. 2005. Endothelial progenitor cells for vasculogenesis. Physiology 20:36-42.

Nilius B, Vriens J, Prenen J, Droogmans G, Voets T. 2004. TRPV4 calcium entry channel: a paradigm for gating diversity. Am J Physiol Cell Physiol 286(2):C195-C205.

Pla AF, Avanzato D, Munaron L, Ambudkar IS. 2012a. Ion channels and transporters in cancer. 6. Vascularizing the tumor: TRP channels as molecular targets. Am J Physiol Cell Physiol 302(1):C9-C15.

Pla AF, Grange C, Antoniotti S, Tomatis C, Merlino A, Bussolati B, Munaron L. 2008. Arachidonic acid-induced $\mathrm{Ca} 2+$ entry is involved in early steps of tumor angiogenesis. Mol Cancer Res 6(4):535-545.

Pla AF, Ong HL, Cheng KT, Brossa A, Bussolati B, Lockwich T, Paria B, Munaron L, Ambudkar IS. 2012b. TRPV4 mediates tumor-derived endothelial cell migration via arachidonic acidactivated actin remodeling. Oncogene 31(2):200-212.

Schierling W, Troidi K, Apfelbeck H, Troidl C, Kasprzak PM, Schaper W, Schmitz-Rixen T. 2011. Cerebral Arteriogenesis is Enhanced by Pharmacological as Well as Fluid-Shear-Stress Activation of the Trpv4 Calcium Channel. Eur J Vasc Endovasc Surg 41(5):589-596.

Sonkusare SK, Bonev AD, Ledoux J, Liedtke W, Kotlikoff MI, Heppner TJ, Hill-Eubanks DC, Nelson MT. 2012. Elementary Ca2+ Signals Through Endothelial TRPV4 Channels Regulate Vascular Function. Science 336(6081):597-601.

Sullivan MN, Francis M, Pitts NL, Taylor MS, Earley S. 2012. Optical recording reveals novel properties of GSK1016790A-induced vanilloid transient receptor potential channel TRPV4 activity in primary human endothelial cells. Mol Pharmacol 82(3):464-472.

Sánchez-Hernández Y, Laforenza U, Bonetti E, Fontana J, Dragoni S, Russo M, Avelino-Cruz JE, Schinelli S, Testa D, Guerra G, Rosti V, Tanzi F, Moccia F. 2010. Store-operated Ca(2+) entry is expressed in human endothelial progenitor cells. Stem Cells Dev 19(12):1967-1981.

Thodeti CK, Matthews B, Ravi A, Mammoto A, Ghosh K, Bracha AL, Ingber DE. 2009. TRPV4 Channels Mediate Cyclic Strain-Induced Endothelial Cell Reorientation Through Integrin-toIntegrin Signaling. Circ Res 104(9):1123-U1278.

Tiruppathi C, Ahmmed GU, Vogel SM, Malik AB. 2006. Ca2+ signaling, TRP channels, and endothelial permeability. Microcirculation 13(8):693-708. 
Troidl C, Nef H, Voss S, Schilp A, Kostin S, Troidl K, Szardien S, Rolf A, Schmitz-Rixen T, Schaper W, Hamm CW, Elsaesser A, Moellmann H. 2010. Calcium-dependent signalling is essential during collateral growth in the pig hind limb-ischemia model. J Mol Cellular Cardiol 49(1):142151.

Troidl C, Troidl K, Schierling W, Cai W-J, Nef H, Moellmann H, Kostin S, Schimanski S, Hammer L, Elsaesser A, Schmitz-Rixen T, Schaper W. 2009. Trpv4 induces collateral vessel growth during regeneration of the arterial circulation. J Cell Mol Med 13(8B):2613-2621.

Vriens J, Watanabe H, Janssens A, Droogmans G, Voets T, Nilius B. 2004. Cell swelling, heat, and chemical agonists use distinct pathways for the activation of the cation channel TRPV4. Proc Natl Acad Sci U S A 101(1):396-401.

Willette RN, Bao W, Nerurkar S, Yue T-1, Doe CP, Stankus G, Turner GH, Ju H, Thomas H, Fishman CE, Sulpizio A, Behm DJ, Hoffman S, Lin Z, Lozinskaya I, Casillas LN, Lin M, Trout REL, Votta BJ, Thorneloe K, Lashinger ESR, Figueroa DJ, Marquis R, Xu X. 2008. Systemic activation of the transient receptor potential vanilloid subtype 4 channel causes endothelial failure and circulatory collapse: Part 2. J Pharmacol Exp Ther 326(2):443-452.

Yoder MC. 2012a. Human endothelial progenitor cells. Cold Spring Harbor perspectives in medicine 2(7).

Yoder MC. 2012b. Human endothelial progenitor cells. Cold Spring Harb Perspect Med 2(7):a006692.

Zaninetti R, Fornarelli A, Ciarletta M, Lim D, Caldarelli A, Pirali T, Cariboni A, Owsianik G, Nilius B, Canonico PL, Distasi C, Genazzani AA. 2011. Activation of TRPV4 channels reduces migration of immortalized neuroendocrine cells. J Neurochem 116(4):606-615.

Zheng X, Zinkevich NS, Gebremedhin D, Gauthier KM, Nishijima Y, Fang J, Wilcox DA, Campbell WB, Gutterman DD, Zhang DX. 2013. Arachidonic acid-induced dilation in human coronary arterioles: convergence of signaling mechanisms on endothelial TRPV4-mediated Ca2+ entry. $\mathrm{J}$ Am Heart Assoc 2(3): 000080 


\section{FIGURE LEGENDS}

Figure 1. Expression of TRPV4 transcript and protein in ECFCs. A, gel electrophoresis of PCR products. Representative semiquantitative RT-PCR of TRPV4. Reverse transcription was performed in the presence $(+)$ or absence $(-)$ of reverse transcriptase enzyme. TRPV4 mRNA expression was normalized to $\beta$-actin. The 246 and 146 bp bands correspond to the TRPV4 and $\beta$ actin-specific PCR products, respectively. MW: molecular weight marker. B, representative western blots showing TRPV4 and $\beta$-actin expression in normal human microvascular ECs (HMEVC-d, HMEVC-c) and EPCs.

Figure 2. GSK stimulates $\boldsymbol{C a}^{2+}$ inflow in EPCs. A, GSK $(20 \mathrm{nM})$ induces a transient elevation in $\left[\mathrm{Ca}^{2+}\right]_{\mathrm{i}}$ in EPCs. $\mathrm{B}$, the $\mathrm{Ca}^{2+}$ response to GSK arises in the presence, but not in the absence $\left(0 \mathrm{Ca}^{2+}\right)$, of extracellular $\mathrm{Ca}^{2+}$. C, 30 min pre-treatment with RN-1734 (20 $\left.\mu \mathrm{M}\right)$ inhibits GSK-induced $\mathrm{Ca}^{2+}$ entry, which promptly resumes upon drug washout. D, 30 min pre-incubation with ruthenium red (RR; 10 $\mu \mathrm{M})$ reversibly prevents GSK-evoked $\mathrm{Ca}^{2+}$ entry.

Figure 3. PMA triggers $\boldsymbol{C a}^{2+}$ entry in EPCs. A, PMA $(10 \mu \mathrm{M})$ evokes a sustained increase in $\left[\mathrm{Ca}^{2+}\right]_{\mathrm{i}}$ in circulating EPCs. B, PMA-evoked $\mathrm{Ca}^{2+}$ signals rapidly return to the baseline upon removal of the agonist from the bath. C, PMA does not elicit any detectable increase in $\left[\mathrm{Ca}^{2+}\right]_{\mathrm{i}}$ in the absence of extracellular $\mathrm{Ca}^{2+}\left(0 \mathrm{Ca}^{2+}\right)$; restitution of $\mathrm{Ca}^{2+}$ to the external solution quickly resumes the $\mathrm{Ca}^{2+}$ response. D, removal of extracellular $\mathrm{Ca}^{2+}\left(0 \mathrm{Ca}^{2+}\right)$ reversibly abolishes PMA-induced elevation in $\left[\mathrm{Ca}^{2+}\right]_{\mathrm{i}}$. E, 10 min pre-incubation with ruthenium red $(\mathrm{RR} ; 10 \mu \mathrm{M})$ prevents PMA-evoked $\mathrm{Ca}^{2+}$ signalling until drug removal from the perfusate. $\mathrm{F}$, the acute addition of ruthenium red (RR; $10 \mu \mathrm{M})$ abrogates the $\mathrm{Ca}^{2+}$ response to PMA. G, 10 min pre-incubation with capsazepine $(10 \mu \mathrm{M})$ does not 
alter PMA-induced increase in $\left[\mathrm{Ca}^{2+}\right]_{\mathrm{i}} . \mathrm{H}$, mean $\pm \mathrm{SE}$ of the amplitude of PMA-evoked $\mathrm{Ca}^{2+}$ signals in the presence and absence of capsazepine.

Figure 5. Intracellular $\mathrm{Ca}^{2+}$ mobilization does not support GSK-induced $\mathrm{Ca}^{2+}$ inflow in EPCS. $\mathrm{Ca}^{2+}$ response to GSK $(20 \mathrm{nM})$ in the absence (A) and presence of (B) of cyclopiazonic acid $(\mathrm{CPA} ; 10 \mu \mathrm{M})$, which blocks SERCA activity thereby depleting the endogenous $\mathrm{Ca}^{2+}$ reservoir. $\mathrm{C}$, mean $\pm \mathrm{SE}$ of the amplitude of GSK-induced $\mathrm{Ca}^{2+}$ signals under the designated treatments. $\mathrm{Ca}^{2+}$ response to GSK $(20 \mathrm{nM})$ in the absence (D) and presence of (E) of 2-APB $(50 \mu \mathrm{M})$, which blocks InsP3Rs and prevents intracellular $\mathrm{Ca}^{2+}$ discharge. $\mathrm{F}$, mean $\pm \mathrm{SE}$ of the amplitude of GSK-induced $\mathrm{Ca}^{2+}$ signals under the designated treatments.

Figure 6. The effect GSK, ruthenium red and RN-1734 on EPC proliferation. A, GSK (20 $\mathrm{nM}$ ) does not stimulate ECFC proliferation after three days in culture. As a positive control the cells have been grown in the presence of the growth factors-enriched medium EGM-2. B, VEGF (10 ng/ml) induces ECFC proliferation in the absence, but not in the presence, of BAPTA $(30 \mu \mathrm{M})$. BAPTA was added 30 min before challenging the cells with VEGF to buffer intracellular $\mathrm{Ca}^{2+}$ levels, as shown in (Dragoni et a., 2011). C, mean \pm SE of the percentage of EPC growth in the presence of EGM-2, ruthenium red (RR; $10 \mu \mathrm{M}), \mathrm{RN}-1734\left(20 \mu \mathrm{M}\right.$; RN), BTP-2 $(20 \mu \mathrm{M}), \mathrm{La}^{3+}(10 \mu \mathrm{M})$ and $\mathrm{Gd}^{3+}(10 \mu \mathrm{M})$. *, compared with control and after Bonferroni’s correction (Student's t test for unpaired samples). 


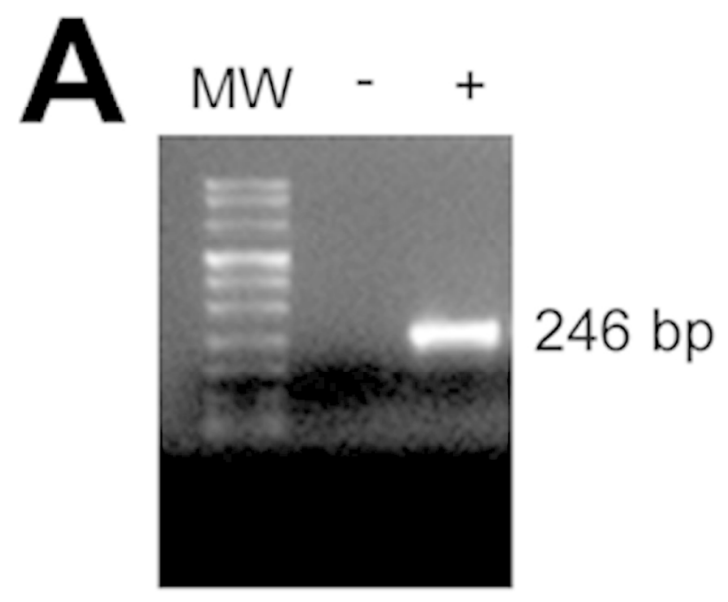

$$
\text { TRPV4 }
$$
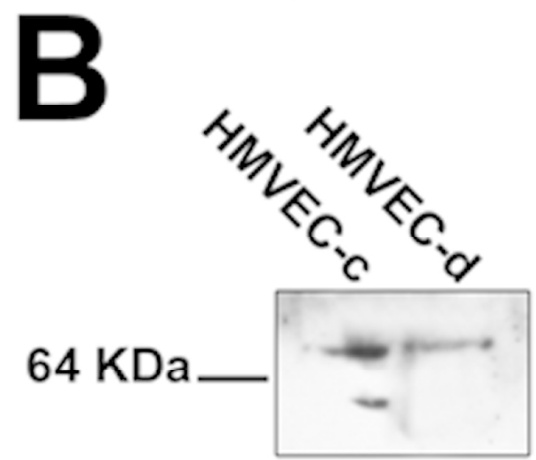

$51 \mathrm{KDa}$
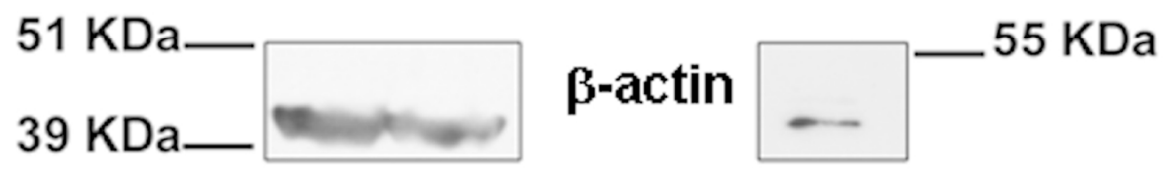

$131 \times 137 \mathrm{~mm}(300 \times 300$ DPI $)$

John Wiley \& Sons, Inc. 

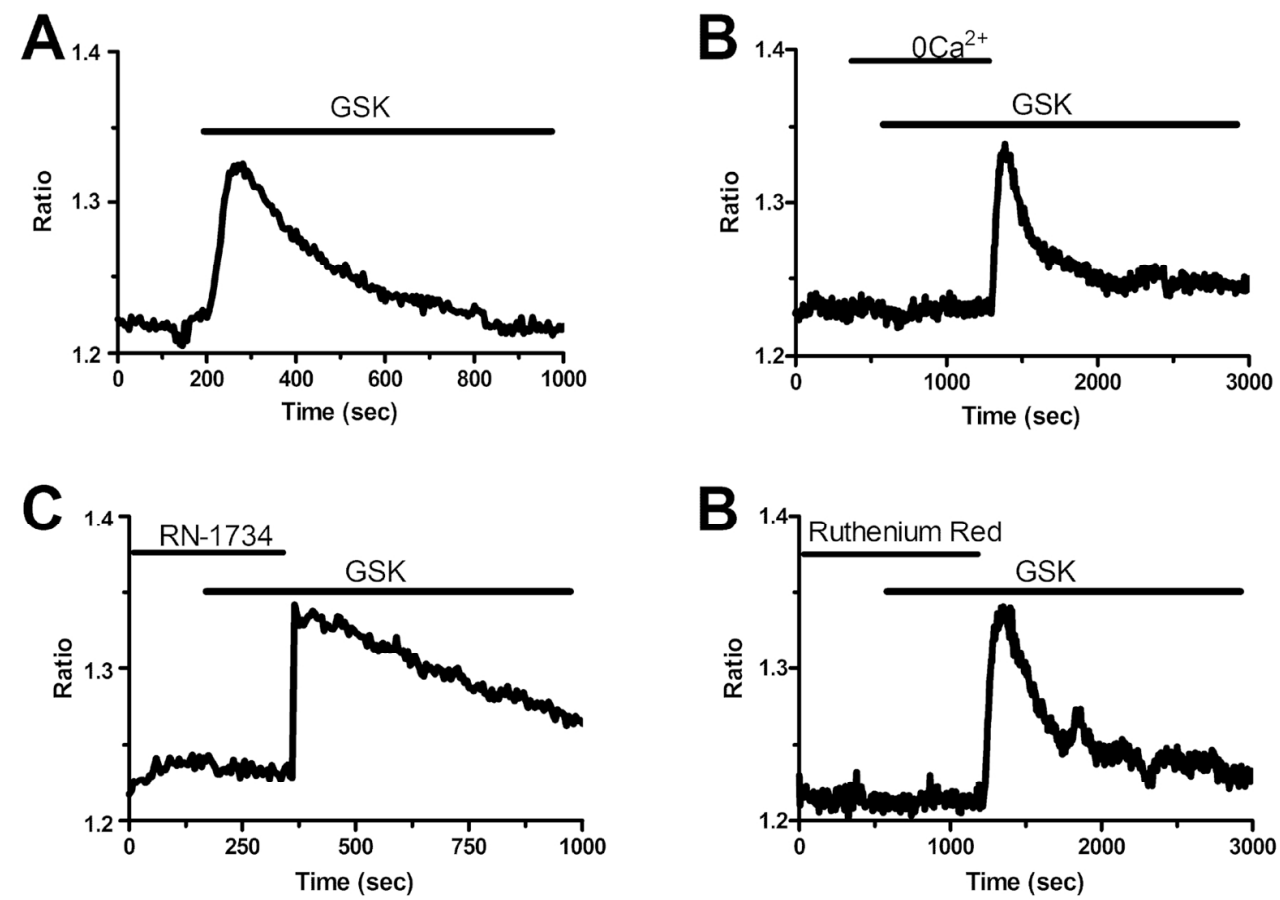

$150 \times 107 \mathrm{~mm}(300 \times 300$ DPI $)$

John Wiley \& Sons, Inc. 

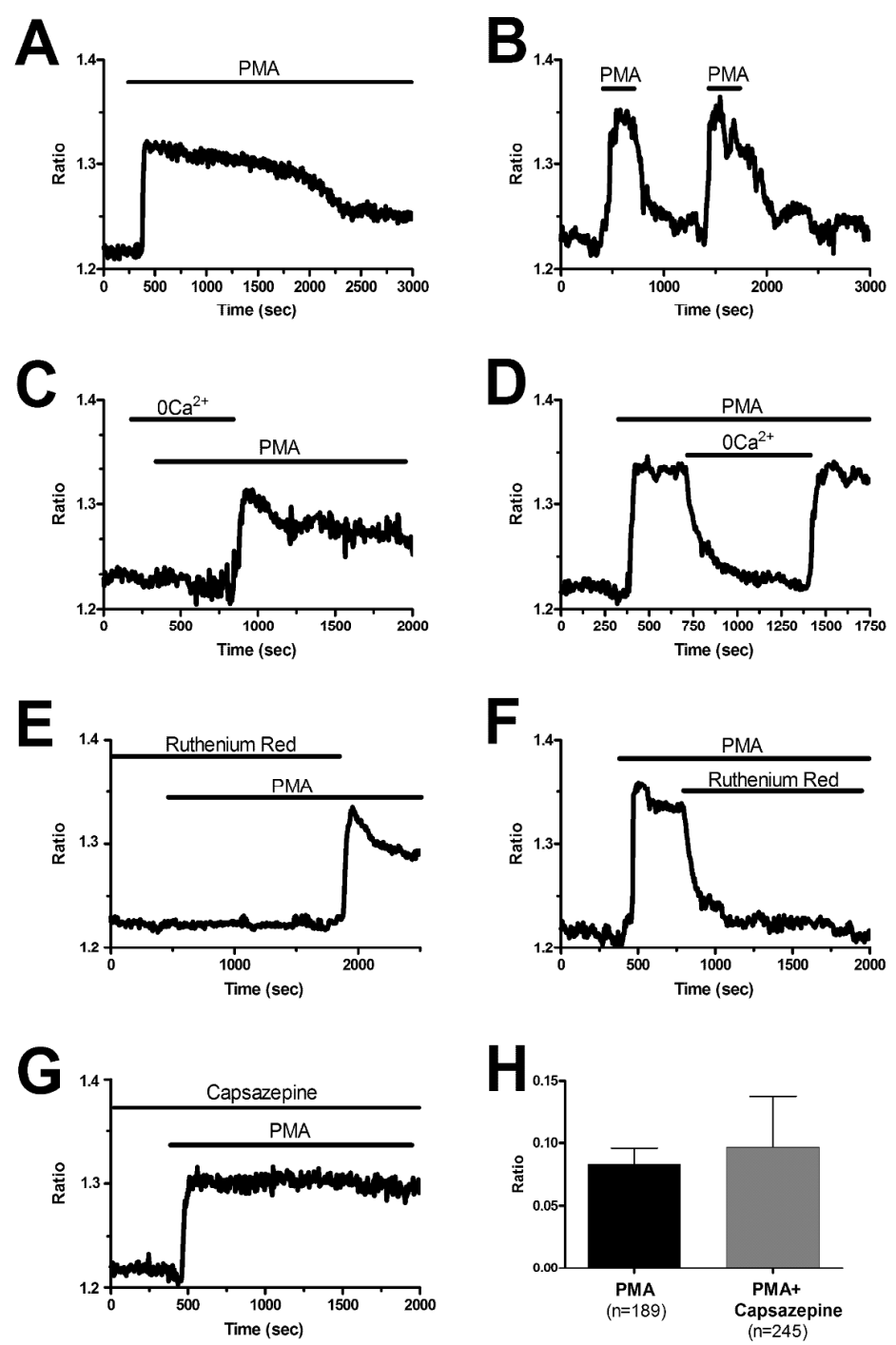

Dragoni et al. - Figure 3

$259 \times 399 m m(300 \times 300$ DPI $)$

John Wiley \& Sons, Inc. 

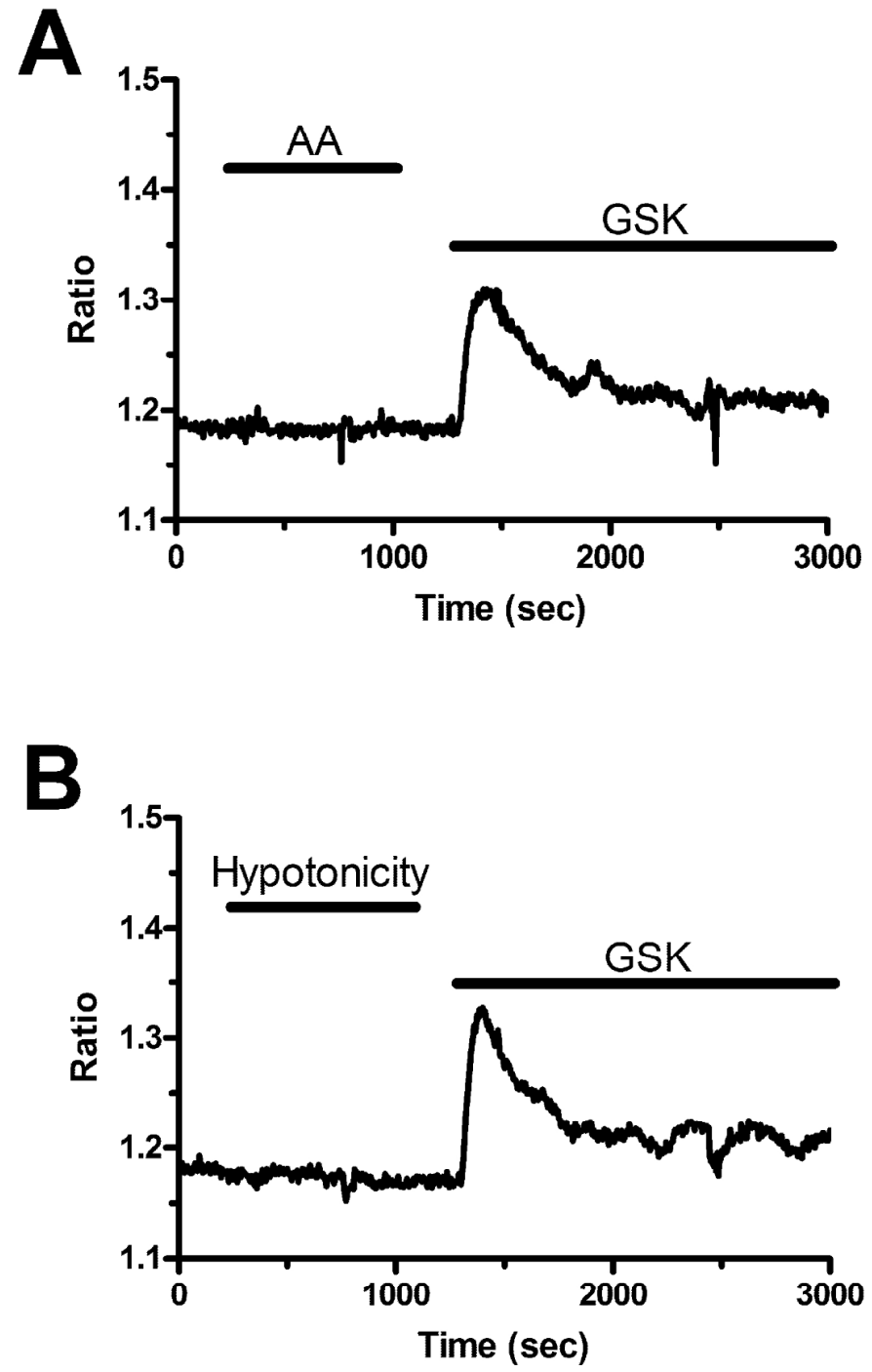

Dragoni et al. - Figure 4

$150 \times 233 \mathrm{~mm}(300 \times 300$ DPI $)$

John Wiley \& Sons, Inc. 

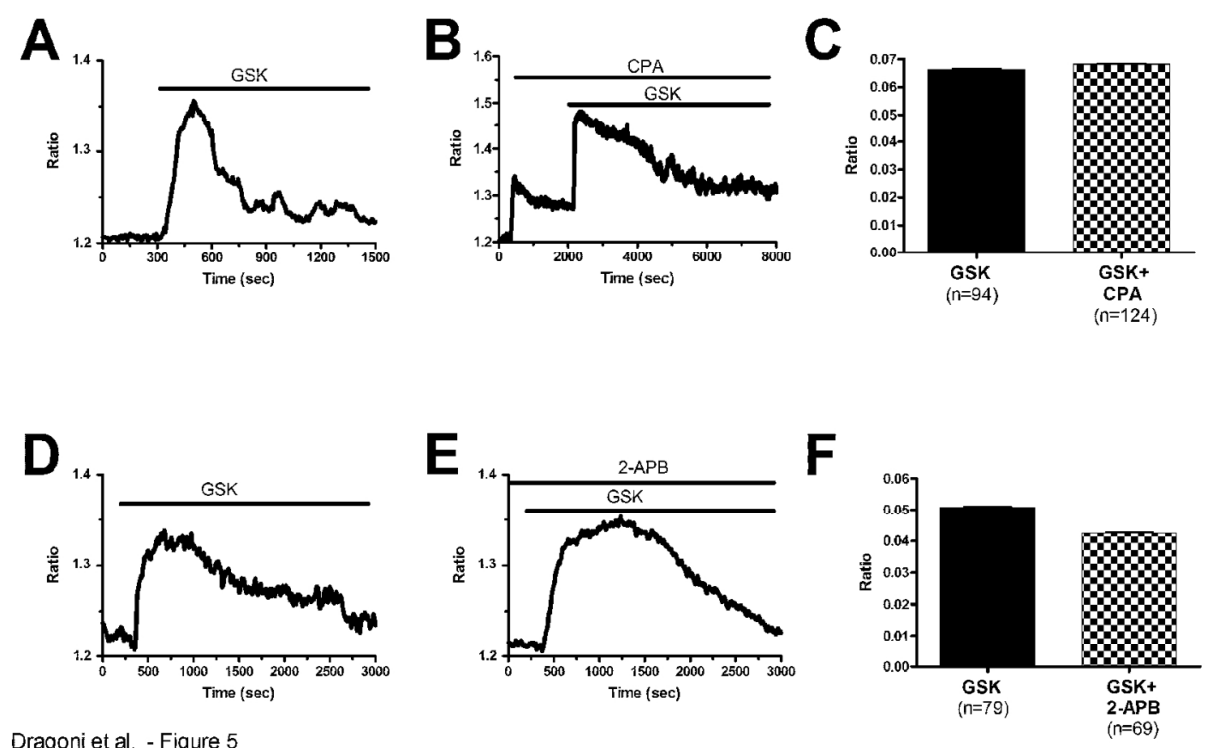

Dragoni et al. - Figure 5

$150 \times 92 \mathrm{~mm}(300 \times 300$ DPI $)$

John Wiley \& Sons, Inc. 

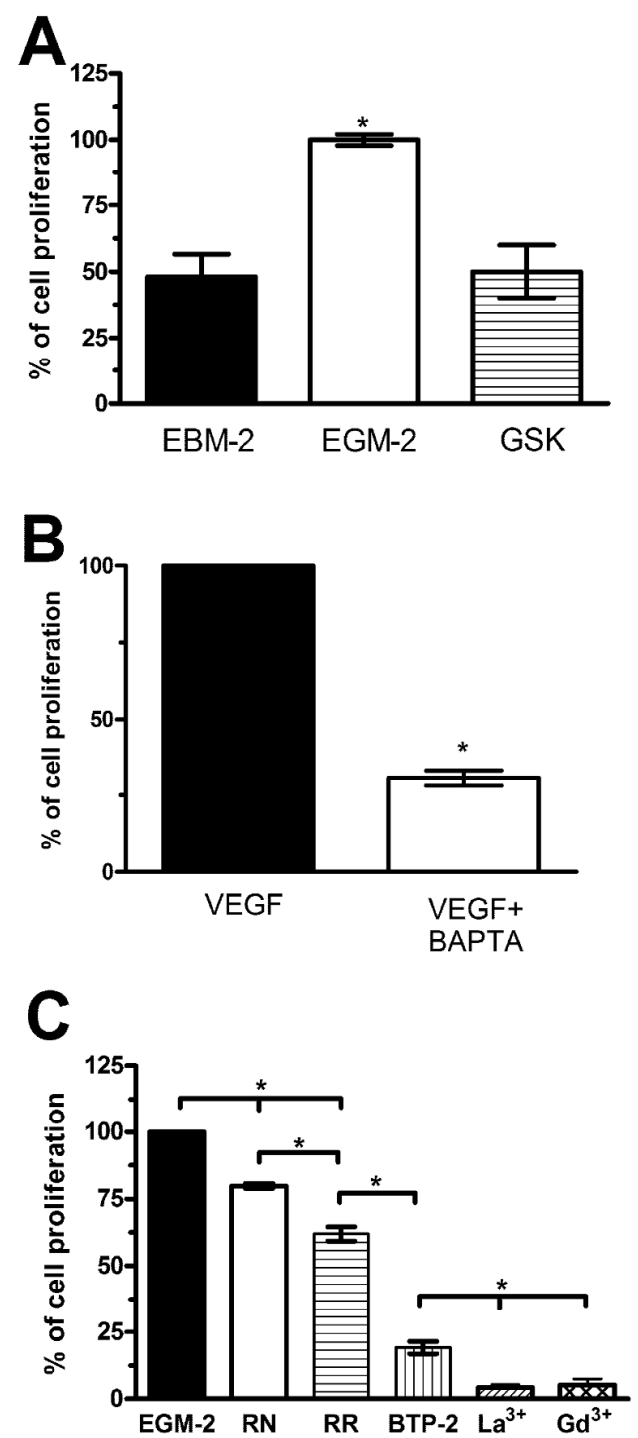

Dragoni et al. - Figure 6

$150 \times 257 \mathrm{~mm}(300 \times 300$ DPI $)$

John Wiley \& Sons, Inc. 